\title{
INFLUENCIADOR DIGITAL: DESAFIO E PERSPECTIVAS ${ }^{1}$
}

\author{
DIGITAL INFLUENCER: CHALLENGES AND PERPECTIVES
}

\author{
Liana Bohrer Berni ${ }^{2}$ e Laisa Oberto Taschetto ${ }^{3}$
}

\section{RESUMO}

Com o avanço da tecnologia, os diversos segmentos de mercado encontraram espaço para rentabilizar as interações sociais desenvolvidas através da internet. Surgem então novas profissões, entre elas a de Influenciador Digital. O presente artigo buscou realizar uma pesquisa e reflexão sobre a carreira de Influenciador Digital, que surgiu como um fenômeno nas redes sociais, em uma cidade do interior do estado do Rio Grande do Sul. Objetivou-se conhecer a realidade desses profissionais, analisar as rotinas, investimentos de custo e retorno financeiro, assim como dificuldades e realizações na carreira. Para tanto, o artigo possui caráter qualitativo exploratório, com as entrevistas realizadas através de um questionário semiestruturado, abrangendo também referencias bibliográficos. Os resultados mostraram que os influenciadores digitais possuem um alto poder de influência e inspiração para os seguidores, rentabilizando a profissão através da publicação e divulgação de produtos, com um baixo custo de investimento inicial. Além disso, constatou-se que os principais desafios da carreira se referem a necessidade de agradar, assim como a falta de entendimento da profissão. Quanto as realizações, destacou-se o contato e conexão com o público, assim como o reconhecimento, apesar de ainda ser necessário uma maior construção da valorização da profissão.

Palavras-chave: Internet, Mercado de Trabalho, Profissão.

\section{ABSTRACT}

With the advance of the technology, various segments of the market found space in order to monetize the social interactions, developed by the internet. Thus, some new professions came up, like the Digital Influencer. The present article aimed to realize a research and reflection about this career, being a phenomenon in the social media on a city in the interior of the state of Rio Grande do Sul. The objective of this work was to know the reality of these professionals, analyze their routine, investments of cost and financial feedback as well as their difficulties and achievements in career. For this purpose, the article has qualitative and exploratory nature with the interview made from a semistructured questionnaire also covering bibliographic references. The results show that the digital influencers have a high influence and inspire their followers, capitalizing the profession by the publications and divulgations of products with a low cost of initial investment. Besides, was determined that the main challenges of this career refers to the necessity of please, as well as the lack of understanding of the profession. Concerning the realizations, was highlighted the contact and the connection to the public, the recognition, besides still be necessary a greater construction of the valorization of the profession.

Keywords: Internet, Market, Profession.

1 Trabalho Final de Graduação.

2 Professora Orientadora do curso de Psicologia da Universidade Franciscana - UFN. E-mail: libberni@hotmail.com 3 Acadêmica do curso de Psicologia da Universidade Franciscana - UFN. E-mail: laisataschetto@gmail.com 


\section{INTRODUÇÃO}

No decorrer do tempo, o trabalho em nossa sociedade tem passado por algumas alterações. Podemos considerar que essas transformações são de grande parte decorrentes do avanço tecnológico e de novos arranjos de trabalho (KUBO \& GOUVÊA, 2012). Independente da época ou profissão, o trabalho é composto por aspectos positivos e negativos, originando prazeres e sofrimentos, e este não significa apenas um meio de subsistência, mas também uma forma de realização pessoal (FERREIRA, 2010).

Diante dos serviços e oportunidades que a internet proporciona, o ser humano se tornou cada vez mais conectado, o que contribuiu para que as relações sociais também ocorressem no meio online, surgindo assim as redes sociais na internet, onde as pessoas podem interagir e ter voz ativa. A partir de então, pessoas dos mais variados segmentos encontraram nas mídias sociais oportunidades de transformar essa interação social em uma atividade rentável. Nesse sentido, quem antes era apenas espectador, torna-se também produtor de conteúdo e informação, recebendo o nome de Influenciador (a) Digital (LIMA, 2016).

Sendo assim, com o crescimento da tecnologia, e as possibilidades encontradas nas redes sociais de influenciar e ser influenciado, esse espaço tornou-se favorável ao surgimento de um novo mercado, trazendo diversas formas de comunicação e rentabilidade (QUIRINO \& PINHEIRO, 2017). Esse novo modelo de mercado surge quando as empresas observam nos Influenciadores Digitas um alto poder de inspirar e instigar o interesse de consumidores, possibilitando às marcas um espaço de conexão discreta e direta com os seguidores (LIMA, 2016). Desse modo, o presente artigo buscou realizar uma pesquisa e reflexão acerca da realidade de profissionais que buscam consolidar uma carreira de influenciador digital.

A escolha do presente tema pode ser justificada a partir do interesse em estudar a recente profissão de Influenciador Digital, que surgiu como um fenômeno nas redes sociais e cada vez atrai mais os interesses do público e de empresas. Além disso, é de grande relevância compreender as transformações do mundo do trabalho e perceber como novas profissões, assim como esta, ganharam seu espaço no mercado e estão se desenvolvendo e rentabilizando-se.

Esse mercado de trabalho pode ser considerado recente, tornando-se necessários debates e reflexões mais variados e que ampliem esse tema em múltiplas áreas de conhecimento que comtemplem o trabalho humano (FERREIRA, GRANGEIRO \& PEREIRA, 2019). Sendo assim, o presente artigo tem por objetivo investigar o trabalho do influenciador digital, assim como compreender suas rotinas, investimentos de custo e retorno financeiro e por fim, dificuldades e realizações na carreira. Através dessas reflexões busca-se uma melhor compreensão sobre o surgimento, reconhecimento e funcionamento dessa nova profissão. 


\section{MATERIAL E MÉTODOS}

A presente pesquisa apresenta caráter qualitativo exploratório, onde é um método que posiciona o pesquisador no mundo, consistindo em um conjunto de procedimentos interpretativos que tornam o mundo visível através de entrevistas e conversas. O projeto foi aprovado pelo Comitê de Ética em Pesquisa, CAAE 26508019.2.0000.5306.

Foram entrevistados influenciadores digitais que residem no interior do estado do Rio Grande do Sul, através de uma amostragem por conveniência, que consiste em utilizar os elementos ou dados que estão disponíveis, e de melhor acesso (MOURÃO, 2009). A coleta dos dados aconteceu no período de abril de 2020 a junho de 2020.

As entrevistas ocorrerem de modo virtual, por vídeo, através da rede social WhatsApp, onde foram acordados dias e horários para a sua realização, de modo a não modificar a rotina dos entrevistados. Como os entrevistados já possuem visibilidade no meio pesquisado, o contato foi feito através da rede social Instagram, onde foi realizado um convite para participação destes. Após o aceite em participar da entrevista, foi enviado o Termo de Consentimento Livre e Esclarecido, para que pudessem ler, assinar e retornar uma via para a pesquisadora. Assim, foi agendado um dia e horário para que ficasse bom para o participante realizar a entrevista.

Os participantes da pesquisa foram cinco influenciadores digitais do interior do estado do Rio Grande do Sul, contemplando influenciadores de ambos os sexos, com no mínimo dez mil seguidores na rede social Instagram, de 25 a 33 anos de idade. Os dados dos sujeitos entrevistados podem ser conferidos no Quadro 1, identificados com letra fictícia afim de preservar suas identidades.

Quadro 1 - Perfil dos Entrevistados.

\begin{tabular}{|c|c|c|c|c|c|}
\hline Entrevis-tado(a) & Idade & Sexo & $\begin{array}{l}\text { Tempo de carreira como } \\
\text { influencia-dor(a) digital }\end{array}$ & $\begin{array}{l}\text { Ramo como influen- } \\
\text { cia-dor(a) digital }\end{array}$ & $\begin{array}{c}\text { Outra profissão } \\
\text { em exercício }\end{array}$ \\
\hline A & 33 anos & Feminino & 8 anos & $\begin{array}{l}\text { Cuidados com a } \\
\text { saúde e beleza }\end{array}$ & $\begin{array}{c}\text { Jornalista e } \\
\text { empreendedora }\end{array}$ \\
\hline $\mathrm{B}$ & 30 anos & Feminino & 4 anos & Estilo de vida & - \\
\hline $\mathrm{C}$ & 27 anos & Feminino & 2 anos & Cuidados com a pele & Empresária \\
\hline $\mathrm{D}$ & 25 anos & Masculino & 4 anos & Moda e estilo de vida & $\begin{array}{c}\text { Assessoria de } \\
\text { Marketing Digital }\end{array}$ \\
\hline $\mathrm{E}$ & 28 anos & Feminino & 2 anos & $\begin{array}{l}\text { Pessoas com defi- } \\
\text { ciência }\end{array}$ & - \\
\hline
\end{tabular}

Fonte: Dados coletados na entrevista.

Com o objetivo de não limitar a fala dos entrevistados e de proporcionar um ambiente em que se sentisse à vontade, foi utilizada uma entrevista semiestruturada. Conforme a autorização dos entrevistados, foi utilizado um gravador de áudio para um registro mais preciso das respostas. Por fim, foi realizada a transcrição da entrevista e uma análise dos dados coletados para aproveitamento na presente pesquisa, realizando uma correlação das respostas obtidas com a 
teoria pesquisada. Após a finalização da análise, o material foi devidamente descartado. O tempo médio de entrevista foi de 30 minutos.

Após a coleta do material foi realizada a análise e interpretação do mesmo. A análise e discussão dos resultados é realizada posteriormente à coleta de dados na escuta, e tem seu começo no momento da transcrição do material coletado através de gravação no momento das entrevistas, visando transformar em uma linguagem escrita, para então, tal documento ser examinado. Para garantir a fidedignidade e valor das descobertas, é recomendado que a verificação e argumentação ocorra somente após a escuta e transcrição dos dados adquiridos de forma ética, sigilosa e livre de julgamentos (GIL, 1999).

A análise de conteúdo é dividida em três etapas: pré-análise, exploração dos elementos e interpretação dos resultados obtidos (BARDIN, 2011). A análise dos dados foi dividida em quatro categorias, delimitadas após o levantamento do material e das entrevistas realizadas, sendo elas: O que é ser um influenciador digital; A dinâmica da rotina do influenciador digital; Investimentos e retorno da profissão de influenciador digital: uma análise dos aspectos financeiros da profissão; Realizações e dificuldades da carreira de um influenciador digital: uma análise dos aspectos subjetivos da profissão.

\section{RESULTADOS E DISCUSSÕES}

\section{O QUE É SER UM INFLUENCIADOR DIGITAL}

A comunicação através da internet ganha cada vez mais lugar, criando assim um novo espaço de exploração do mercado. A criação da informação e distribuição em tempo real, faz com que esse lugar ganhe grande visibilidade, sendo, através dessa interação, possível que a informação circule horizontalmente e com mais facilidade, tornando-se um campo atrativo para novas profissões (VILCHES, 2002).

Um influenciador digital se refere às pessoas que influenciam o outro digitalmente simplesmente por existir. São conhecidos e acessados em redes sociais, como Instagram ou Twitter, e normalmente começam mostrando suas vidas e seu ponto de vista para os seguidores, que acabam se identificando com aquela pessoa (MOREIRA \& RIOS, 2016). Para os entrevistados, ser influenciador digital é:

\footnotetext{
É bem como a própria palavra diz né, é tu influenciar as pessoas né, mas o que eu penso é sempre de uma forma positiva. Então o que eu posso levar pras pessoas que me seguem né, através desse canal de comunicação, principalmente do Instagram. (Entrevistada A)
}

Através da fala da entrevistada, podemos perceber que ser um influenciador digital é influenciar as pessoas que acompanham o conteúdo postado nas redes sociais, de modo a levar os seguidores a consumir produtos ou simplesmente o estilo de vida exposto. São pessoas comuns, que compartilham suas vidas e interagem com o público. 
A finalidade de um Influenciador Digital é a produção de conteúdo, sem uma análise valorativa, já que este conteúdo pode ser publicado nas mais variadas plataformas digitais, assim como conter diversos formatos. Sendo assim, suas possibilidades de atuação são ampliadas, mas para ocupar esse lugar é preciso que o influenciador produza o conteúdo, tenha consistência nessa produção, mantenha sua relação com o público, obtenha prestígio na comunidade que alcança e influencie, tanto em debates e assuntos, quanto na compra e venda de produtos, ganhando crédito, capital e reputação (KARHAWI, 2017).

Segundo os entrevistados abaixo, ser influenciador está relacionado a criar conteúdo, desse modo:

É tu criar conteúdo. Em primeiro lugar é tu começar a falar e divulgar, criar conteúdo sobre as coisas que tu gosta, que tem afinidade. Tu acaba, a partir do momento que tu passa essa experiência, tu acaba fazendo com que outras pessoas tenham curiosidade também de ter essa mesma experiência, enfim... (Entrevistada B)

Pra mim ser um influenciador digital, eu acho que ta muito relacionado a tu entender que você tem uma responsabilidade muito grande, porque você abre a sua vida pra outras pessoas. (...) É tu tá próximo das pessoas, tu compartilhar conteúdo relevante, conteúdo de qualidade pras pessoas. (Entrevistado D)

A conexão de quem cria conteúdo e dos seguidores é uma via de mão dupla. Eles dialogam com os usuários da internet e por estarem presentes no mesmo meio e conhecer a linguagem do público, conseguem essa ligação (SILVA \& TESSAROLO, 2016). Os entrevistados a seguir explanam sobre a relação entre seguidores e influenciadores:

Influenciador é aquela pessoa que abre a vida dela e que compartilha o dia a dia dela. (...) é tu perceber que a conexão está entre as pessoas (...) tu vai continuar sempre com esse público, com esse público que sempre esteve lá contigo. (Entrevistado D)

"O que eu dizer pra elas é lei." (Entrevistada C)

De acordo com os autores acima, ter um objeto que o influenciador digital usa ou ter o visual parecido, é muito importante para os seus seguidores. Os influenciadores digitais são como uma ponte para as marcas, conectando-a o público. Desse modo, os seguidores que confiam nos influenciadores digitais e no que eles divulgam acabam também confiando na marca divulgada e consumindo, logo que o produto é indicado.

Porém, durante a entrevista, a entrevistada a seguir advertiu:

Eu acho que as vezes a nossa geração não tá acostumada ainda com a influência de outras pessoas, elas não sabem pegar uma dica que eu dou, e pensar naquela dica e na vida delas (...) daí as pessoas vão lá e compram, tipo, elas não pensam muito antes sabe. (Entrevistada C)

Quando um influenciador digital divulga um produto ou usa uma roupa, automaticamente os seguidores aumentam a procura sobre os produtos ou serviços publicados. Os seguidores consomem 
os produtos anunciados por simplesmente confiar e almejar o que o influenciador digital usa (SILVA \& TESSAROLO, 2016). Desse modo os influenciadores digitais "têm redefinido as práticas e dinâmicas dos mercados contemporâneos ao se consolidarem como figuras de destaque no ambiente digital" (KARHAWI, 2016a, p. 39).

Ainda segundo a mesma entrevistada:

"Vejo muita gente querendo saber tipo, de onde que é o meu óculos, de onde que é o meu brinco, sabe (...) Porque as pessoas são muito interessadas em tudo.” (Entrevistada C)

Por fim, os influenciadores digitais sabem como lidar com o seu público. Eles sabem perfeitamente o que o público gosta de ver, o que não dará certo anunciar e principalmente como falar e como conseguir sua atenção (NEVES, 2019). O entrevistado abaixo revela que percebe quando algo agrada seu público:

São dois pontos que eu cuido muito, primeiro se a marca tem a ver comigo, e segundo se a marca tem a ver com o meu público. Porque tem muita coisa que tem a ver comigo, mas que eu vejo que a galera que me segue talvez não vá se identificar. (Entrevistado D)

\section{A DINÂMICA DA ROTINA DO INFLUENCIADOR DIGITAL}

Para um influenciador digital é necessária uma adaptação do espaço de trabalho, equilibrando uma rotina que de adeque a realidade do trabalho em casa e da realidade do trabalhador (RAFALSKI \& ANDRADE, 2015). As entrevistadas a seguir, relatam sobre sua rotina de trabalho, adaptada com outros compromissos profissionais que possuem ao longo do dia:

\footnotetext{
De manhã eu trabalho pra minha loja (...) Ai de tarde é um tempo que eu fico tomando café e falando com as pessoas, respondendo, por áudio ou vídeo, e produzindo conteúdo nos storys né, que eu abro várias caixinhas de perguntas e tudo mais. Daí as vezes eu tiro um tempo pra escrever algum post no blog, porque eu tenho um blog também, (...) mas eu sempre tento mostrar um pouquinho da minha vida, então acaba que eu meio que não tenho rotina assim, daí eu vejo algo legal eu posto. Tento deixar mais natural assim, mas produção de conteúdo sobre cuidados com a pele, eu abro sempre caixinhas de tarde assim. (Entrevistada C)

Varia muito, porque assim, eu confesso que ultimamente nesses últimos meses quando eu resolvi empreender com essa multinacional, eu acabei focando muito mais nisso, porque ela tava me dando muito mais retorno em questões financeiras. (...) então eu consigo assim, classificar os trabalhos que eu vou conseguir dar conta, pra que não atrapalhe no meu trabalho como jornalista ou como empreendedora. (Entrevistada A)
}

Além da adaptação necessária, os influenciadores digitais normalmente exercem uma rotina de forma planejada e constante, realizando publicações todos os dias (DREYER, 2017). Os entrevistados a seguir possuem uma rotina fixa e pré-definida, com a organização de postagens semanais e visitas às empresas: 
Toda semana eu tenho um planner semanal, sabe. Daí eu me organizo, com a rotina de conteúdo, parceiros que eu vou ir, e tal, e anoto na minha agenda. Sempre toda a semana é bem esquematizada, dos parceiros que eu vou visitar e dos conteúdos que eu quero falar. (Entrevistada B)

Eu tenho uma rotina (...) Hoje eu trabalho com visitas nos parceiros (...) então isso já tá no meu planejamento, que eu faço lá no sábado, domingo, que eu planejo toda a agenda da semana. E em meio a isso também tem as campanhas que surgem, quando tal marca entra em contato pra me enviar algum produto. Daí eu vejo na agenda e digo o dia que eu acho mais interessante gravar, daí isso já vai pra agenda. (Entrevistado D)

Eu tenho uma rotina certa. Tenho meu planner que eu planejo toda a semana, e no início do mês eu planejo todo o mês mais ou menos, com posts, que dia vou fazer tal parceiro e tal, e na semana eu organizo direitinho o que eu vou fazer durante a semana. Mas os storys é mais espontâneo assim, da vontade e vou lá fazer, mas eu marco e separo os dias assim, tal dia é de tal loja. (Entrevistada E)

Dessa forma, pode-se perceber que quanto a rotina de trabalho, é possível que seja mais variável, dependendo se o influenciador apresenta outros compromissos que necessite conciliar com a carreira de influenciador digital. Ao mesmo tempo, existem influenciadores digitais com a rotina semanal e diária definida e constante, com o planejamento de publicações, visitas as lojas, e aparições nas redes sociais programadas.

\section{INVESTIMENTOS E RETORNO DA PROFISSÃO DE INFLUENCIADOR DIGITAL: UMA ANÁLISE DOS ASPECTOS FINANCEIROS DA PROFISSÃO}

A internet é utilizada cada vez mais tanto nas relações pessoais quanto de trabalho. Podem ser utilizadas como meio para acessar ou disponibilizar informações, mensagens, ou até mesmo como forma de divulgação e propaganda, sendo um espaço de grandes possibilidades de negócios que possam surgir. Através dessa era digital são possíveis a busca e a realização de trocas entre as pessoas e organizações, de forma rápida, com baixo custo, e com grande potencial de interação direta, facilitando essas relações (CINTRA, 2010).

Para ser um influenciador digital, conquistar popularidade e produzir seu próprio conteúdo não é necessário obrigatoriamente que exista um investimento de bom suporte tecnológico (MOREIRA \& RIOS, 2016). Em relação aos custos de investimento necessários para iniciar a carreira de influenciador digital, o entrevistado destaca:

Na verdade, um celular com uma câmera e uma internet, nem que seja um Wifi, arruma um Wifi (risos). (...) Então hoje em dia eu vejo que tu tendo um celular com câmera e tu tendo internet, tu pode buscar referência em outras pessoas e produzir teu próprio conteúdo. (Entrevistado D) 
Com relação à mesma questão, uma das entrevistadas ainda ressalta outro investimento que considera importante:

Eu acho que um celular já dá tranquilo. O investimento que eu gosto de fazer é em look, por exemplo, tá sempre bem vestida sabe, e isso tudo eu compro, é com o meu dinheiro, não tenho nenhuma loja parceira assim. Então em investimento tecnológico assim, só o celular é tranquilo, tá ótimo. Eu acho interessante também fazer cursos. (Entrevistada E)

A atividade de influenciador digital passou a ser profissionalizada no momento em que recebeu um valor de troca e a ser remunerada financeiramente pelas empresas, quando estas perceberam que existia ali um grande potencial de influenciar no comportamento das pessoas, inclusive na compra de produtos (FERREIRA, GRANGEIRO \& PEREIRA, 2019). Sobre a remuneração financeira da profissão, a entrevistada a seguir explana:

“Hoje em dia, essa é a minha profissão né, eu trabalho disso, me sustento disso.” (Entrevistada B)

Inicialmente os influenciadores publicavam por hobby, sem pretensão de retorno financeiro, entretanto, hoje em dia com a conexão das marcas tornou-se possível a monetização dessas publicações. É através de postagens patrocinadas, fotos, vídeos de publicidade, campanhas e divulgação de produtos, assim como sua própria imagem e tempo, que os influenciadores encontraram uma forma de ganhar dinheiro (KARHAWI, 2016). Em relação à monetização das publicações, uma das entrevistadas adverte:

Eu acho que, claro, depende né. Porque a pessoa não pode começar hoje e já querer um retorno financeiro daqui um mês. É uma coisa a longo prazo, requer muito esforço, tempo, mas eu acho que tem potencial sim de dar retorno financeiro. (Entrevistada C)

Ainda conforme os autores acima, a parceria entre os influenciadores digitais e as marcas proporcionou a ascensão financeira dessas pessoas, visto a grande força e importância na criação de valor para uma empresa que os influenciadores representam. Entretanto, não há um padrão na forma como os comunicadores de conteúdo recebem o retorno financeiro pelos serviços prestados. O entrevistado a seguir comenta:

"Hoje a renda que eu tenho como influenciador digital passa da renda que eu tenho trabalhando pra empresa que eu trabalho.” (Entrevistado D)

Entretanto, é possível perceber pela fala da entrevistada abaixo, que para ela esta realidade é ainda um pouco diferente, evidenciando que não há um padrão de remuneração para a profissão:

"No momento não tô ganhando nada, tô só com a permuta né. (...) nesse início, eu acho que a gente tem que se sujeitar a fazer as permutas e tal, e daí depois com o tempo ir evoluindo né.” (Entrevistada E)

Além disso, pode-se perceber que o empreendedorismo está muito presente na vida dos influenciadores digitais. No âmbito econômico, o empreendedorismo não significa apenas um aumento 
de produção e de renda, também remete a originalidade e a criação de novos arranjos de negócio (HISRICH, PETERS \& SHEPHERD, 2009).

Sendo um novo modelo, o empreendedorismo surge como uma forma de conquistar espaço no mercado de trabalho. Essa nova forma de colocar-se no mercado exige criatividade para buscar soluções e inovações para as oportunidades, assim como independência para agarrar as responsabilidades de seus atos, no lugar de seguir ordens de outras pessoas, e colocar em prática seus próprios esforços (SHANE, LOCK \& COLLINS, 2003). Entende-se que o empreendedor apresenta habilidade em traçar objetivos e encontrar espaços, utilizando sua criação e conhecimento acerca do ambiente que se encontra, para elaborar diferentes negócios e serviços (FILION, 1999).

Diante do exposto, é possível pensar que os influenciadores digitais possuem características de empreendedores, onde recebem prestígio e reputação em um espaço inovador, como a internet, se tornando independente e gerindo seu próprio negócio (OLIVEIRA JUNIOR, 2019). Desse modo, por possuírem tais características, aliam à profissão de influenciadores digital suas próprias empresas, como é o caso das entrevistadas abaixo:

"Eu trabalho como jornalista, como influenciadora digital e empreendo ainda na área do rejuvenescimento." (Entrevistada A).

\footnotetext{
A gente montou uma loja de Skin Care, e daí a gente traz produtos de fora, pra cá pro Brasil (...) como eu gosto muito de Skin Care e gosto de falar sobre isso, vou empreender nesse nicho, que é uma coisa que eu gosto muito. (Entrevistada C)
}

Por fim, um dos entrevistados ainda relata aliar a profissão de influenciador digital com outra carreira:

"Hoje trabalho com Marketing Digital em peso né, tanto com assessoria, com todos os trabalhos que eu faço." (Entrevistado D)

É possível compreender o Marketing Digital como um instrumento de criação de estratégias e propagandas para as empresas, aumentando os lucros, o contato com os clientes e se diferenciando no mercado (COSTA, DIAS, SANTOS, ISHII \& SA, 2015). Sendo assim, o trabalho de influenciador digital perpassa as estratégias de Marketing Digital, onde esse deve divulgar um produto ou serviço, planejando ações de propaganda da marca anunciada, sendo possível associar as duas carreiras e rentabilizá-las, como o entrevistado em questão.

Dessa forma, em relação ao retorno financeiro da profissão, pode-se perceber uma certa discrepância, já que enquanto alguns entrevistados consideram essa monetização satisfatória, outros percebem que ainda não é o suficiente. Essa remuneração pode ter relação com o tempo que o influenciador atua nas redes sociais, visto que alguns entrevistados deixaram explicito que no início da carreira precisam sujeitar-se a ganhar menos. 
A forma como o trabalho se organiza é responsável pelas boas ou duras consequências para o funcionamento psíquico do trabalhador. Sendo assim, no trabalho é possível que se encontre experiências de prazer e/ou sofrimento, que acabam se mostrando através de sintomas particulares em relação ao contexto sócio profissional e a estrutura psíquica do indivíduo (DEJOURS, 1987). Cada pessoa tem uma forma específica de reagir às adversidades encontradas no trabalho, carregando consigo suas histórias pessoais e singularidades (MENDES, 1995).

A respeito das adversidades encontradas na carreira de Influenciador Digital, uma das entrevistadas responde:

Eu sempre falo que as pessoas não sabem conviver na internet. Tipo, tem gente que xinga a outra, haters, tipo, eu nunca recebi haters, mas as vezes eu recebo umas críticas sabe, e isso é tranquilo, mas eu acho que muitas pessoas não sabem conviver na internet. (Entrevistada C)

Para a Psicodinâmica do Trabalho, é importante entender como o trabalhador consegue atingir o equilíbrio psíquico, mesmo que através de um sofrimento. É possível definir este campo como um estudo do sofrimento e das formas e significação deste. Para este autor, o sofrimento é o conflito entre o funcionamento psíquico e mecanismo de defesa do trabalhador, com as pressões sofridas no ambiente de trabalho (DEJOURS, 1992).

A profissão de influenciador digital apresenta uma necessidade de atender as expectativas midiáticas, precisando ser e parecer mais do que já é mostrado na vida online, podendo gerar cansaço e sobrecargas em relação a contentar sempre as expectativas do público (RIBEIRO, 2018). O entrevistado a seguir relata sobre as pressões sofridas pela carreira, assim como a necessidade de agradar:

Eu acho que é um desafio que todo mundo sente, mas eu percebo que por eu trabalhar com a minha imagem, eu sinto muito, que é o fato de por exemplo, tem um dia que aconteceu algo na tua família e tu não ta bem, mas tu precisa gravar e precisa conseguir ta pelo menos um pouco bem sabe. (...) Parece que como tu ta ali, trabalhando com a tua imagem, tu pode ser alvo de qualquer coisa, e tu não pode não estar bem. (Entrevistado D)

Já outra entrevistada entende que sua maior adversidade está na compreensão da profissão:

"Eu acho que é o não entendimento das pessoas por essa profissão. Eu notava que as pessoas no início não entendiam muito, e daí não tinham muito como mensurar, não entendiam o meu papel." (Entrevistada B)

Existe ainda uma outra parte da vinculação do homem com o trabalho, chamada de mobilização subjetiva, onde é considerada uma forma do trabalhador viver o prazer no trabalho, lidando com o sofrimento (MENDES, 2007). O trecho abaixo exemplifica como o prazer e as realizações da 
profissão podem contribuir para que o profissional continue a vivenciar experiências em seu trabalho, encontrando um significado:

Essa conexão, esse contato que eu tenho com as pessoas, eu gosto muito (...). Trabalhar com pessoas, e esse convívio que eu tenho, essa troca de experiências (...) eu aprendo muito com essa convivência, toda essa troca, toda essa conexão que me ensina bastante. É isso que me orgulha em fazer o que eu faço hoje. (Entrevistado D)

O processo de mobilização subjetiva é caracterizado pelo uso dos recursos psíquicos do trabalhador, assim como o uso de espaços para discussão e estudos sobre o trabalho. Para tanto, é preciso que exista uma relação de contribuição e retribuição simbólica por parte dos indivíduos da organização, implicando no reconhecimento da competência do trabalhador, permitindo transformar o sofrimento para resgatar o sentido do trabalho (MENDES, PAZ \& BARROS, 2003). Quanto as realizações na profissão e a retribuição simbólica, a entrevistada a seguir destaca:

Eu acho que a minha maior realização é contato com as pessoas, e as pessoas que eu conheço através das redes sociais. (...). Já sai tomar café, jantar, várias coisas, acho que pra mim a amizade e o poder que o online tem de trazer pro off-line é o meu maior ganho. (Entrevistada A)

Em relação as realizações na profissão aliadas ao resgate de sentido ao trabalho, uma das entrevistadas revela:

É a interação que o público tem comigo, a troca de experiência que a gente tem. Porque eu procuro sempre ta conversando com os meus seguidores, então é esse reconhecimento por parte dos seguidores, o carinho que eu recebo deles, é isso que eu amo, que me fez continuar. (Entrevistada E)

Com o surgimento das redes sociais ficou muito comum que conteúdos relacionados à vida social, profissional e pessoal dos internautas fossem divulgados. Desse modo, são cada vez menos nítidos e possíveis de serem identificados quais os conteúdos referentes a vida pública e quais os conteúdos da vida privada, visto que se misturam, e o que era para ser privado se torna público (EVANGELISTA et al., 2017).

Atualmente esses dois conceitos de privado e público se misturaram, se transformando em homogêneos e de difícil reconhecimento, tornando a vida privada divulgada nas redes sociais. Com o acesso as redes sociais, tudo pode ser encontrado, já que os indivíduos expõem com detalhes a vida pessoal. As redes sociais podem ser consideradas como o lugar em que o pessoal e profissional são misturados, sem barreiras ou divisas que delimitem um ou outro (EVANGELISTA et al., 2017). A seguir, as entrevistadas comentam sobre a fundição de vida privada e pública:

Eu sou o que eu sou sabe, como meu Instagram não é um personagem, sou eu que to ali, eu trabalho comigo, então tudo é junto. (...). Então eu acho que mistura muito, porque tu trabalha muito com a tua imagem, com a tua empolgação, com a tua motivação, e as vezes tu não tá empolgada, mas daí no meu caso eu pego e falo que não to bem. (Entrevistada B) 
Nossa, mistura bastante. É... eu não consigo ficar um dia longe do Instagram (risos). Isso é uma coisa que tipo assim, tá, no final de semana eu me dou folga sabe, mas não é uma obrigação, realmente tudo o que eu posto é porque eu quero compartilhar, porque eu quero conversar com as pessoas. (Entrevistada A)

Na atualidade contemporânea o público e privado são embaralhados, sendo impossível distinguir o que deveria ficar guardado para o sujeito e o que deveria ser mostrado ao público. A influência perpassa pela mesma questão, transitando pela esfera privada e ocupando o cenário do ambiente público (HORNHARDT, 2019). Os influenciadores digitais abrem suas vidas para todos, durante o dia inteiro. A figura do influenciador digital hoje em dia vai além de expor uma opinião sobre algo, eles compartilham hábitos pessoais e rotineiros, divulgando suas vidas privadas a quem desejar ver nas mídias sociais. Eles tornam-se pessoas públicas que aos olhos dos seguidores são possíveis de serem alcançados, tendo essa aproximação decorrente da exposição do pessoal e do compartilhamento da própria vida (EVANGELISTA et al., 2017). Entretanto, para algumas das entrevistadas, é possível que a mistura de vida pessoal e pública de um influenciador digital seja dosada:

Eu acho que eu tento deixar uma mistura saudável sabe (...) Só que eu acho que não se mistura tanto porque eu não sou aquela pessoa que fala dos problemas, sabe, porque acontece muito isso também né, muitos influenciadores têm como conteúdo a vida deles. Já eu não, o meu conteúdo é diferente de mim, então quando eu tenho problema eu não venho e falo lá nos storys sabe. (Entrevistada C)

"Eu procuro separar bastante sabe. Não sou aquelas que fica o tempo inteiro com o celular pensando “ai meu deus eu preciso postar", então eu consigo separar bem sabe.” (Entrevistada E).

Diante desse novo modo de ter visibilidade, os limites são diluídos. As questões intimas e privadas são midiatizadas, tornando-se performáticas e espetacularizadas. Tudo o que envolve o cotidiano é exposto, incluindo o que antes era dito como reservado (THOMPSON, 2013). Dessa forma, os influenciadores postam e exibem suas vidas nas mídias, evidenciando muito mais momentos felizes e de beleza do que momentos de sofrimento (HORNHARDT, 2019). Diante desse cenário, as entrevistadas abaixo comentam sobre mostrar os momentos de sofrimento e a aglutinação de público e privado:

Se eu não to legal e eu não quero aparecer eu não apareço, simplesmente, sabe... Eu sei que tem pessoas que falam das bad, mas eu não gosto, eu gosto de trazer alegria, felicidade. E se realmente eu não to bem, eu fico neutra assim. (Entrevistada A)

Até quando eu não to muito bem eu comento, que não to num dia legal, tento ser bem sincera nesse sentido. (...). Porque tem algumas coisas que eu não quero compartilhar, se tem algo que eu não quero não falo, entendeu.... Tem sim como separar ou não, mas daí vai de tu querer. (Entrevistada B)

Outro ponto a ser destacado referente a prazeres e sofrimentos no trabalho é o reconhecimento, que pode ser considerado como uma realização do "eu" no campo do social. Sendo assim, ser 
reconhecido tem ligação direta com a construção de identidade do indivíduo, implicando no julgamento do outro (GERNET \& DEJOURS, 2011). Sobre o reconhecimento da profissão, a respeito do julgamento do outro, a entrevistada relata:

Eu acho que nesse momento que a gente ta agora, acabou se tornando de uma coisa meio negativa, que as vezes algumas pessoas ainda acham que não é trabalho, que a gente não trabalha sabe, pra uma coisa mais positiva. (Entrevistada C)

O reconhecimento é de grande importância para a construção de identidade e de saúde e prazer, onde a falta desta pode acarretar em sofrimento, despersonalização e adoecimento do sujeito no trabalho (BENDASSOLLI, 2012). Podemos considerar como reconhecimento um processo que valoriza o esforço investido e o sofrimento adquirido pelo sujeito ao realizar determinado trabalho, propiciando ao sujeito que este construa sua identidade, vivenciando uma realização de si mesmo (MENDES, 2007). A respeito da valorização da profissão como trabalho e de esforço investido, o entrevistado comenta:

Hoje eu me vejo muito reconhecido, muito mais do que era antes (...) eu vejo que tem reconhecimento, mas ainda tem também muito aquele estigma do blogueirinho, porque culturalmente tem isso muito forte né. (...) Mas hoje as pessoas entendem mais que ser blogueirinha é um trabalho, é uma profissão, tem seu peso, tem sua responsabilidade assim como qualquer outra. (Entrevistado D)

Para Dejours, o reconhecimento advém do julgamento da qualidade do trabalho que foi realizado e não se refere diretamente à pessoa, porém esse reconhecimento pode significar ganhos no campo do registro identitário. Esse julgamento representa o valor e a validação que o outro atribui ao trabalho do sujeito, tornando possível trazer um novo significado ao sofrimento (BENDASSOLLI, 2012). Em relação ao respeito e o valor da carreira de influenciador digital, segundo a entrevistada:

Algumas pessoas ainda tem um certo preconceito (...) mas acho também que muitas pessoas já entendem que existem influenciadores digitais, que trabalham com essa produção de conteúdo e tal. (Entrevistada B)

Muitas vezes a profissão de influenciador digital é confundida com lazer e não considerada como trabalho, e também associada à níveis de empenho e esforço menores (FERREIRA, GRANGEIRO \& PEREIRA, 2019). Entretanto, o reconhecimento dos seguidores é evidente, já que os influenciadores digitais representam de certa forma um papel de líder, que ditam o que o seu público deve seguir. Eles são considerados exemplos a serem seguidos por seus seguidores, pois apresentam interesses e características parecidas às de quem acompanha suas postagens (JÁCOME, 2019). A entrevistada abaixo comenta sobre a profissão por vezes não ser considerada trabalho:

Eu acho que ainda existe assim uma precariedade, mas vai muito do influenciador escolher de que forma ele vai fazer os seus trabalhos. Porque tipo, as empresas quanto menos elas 
puderem investir, melhor. (...) Mas eu vejo que hoje tem mudado muito, porque hoje em dia eles até consideram como profissão sabe, porque existem pessoas que se dedicam só a isso. (Entrevistada A)

Entretanto a seguinte entrevistada relata que avanços na valorização da profissão ainda são necessários:

Eu acredito que as pessoas já reconhecem como profissão, mas ainda tem muito a melhorar né. Como eu falei, no sentido da remuneração, dinheiro, enfim, em relação aos parceiros né. (Entrevistada E)

Dessa forma, a partir das entrevistas, podemos compreender que apesar dos desafios e dificuldades da profissão, os influenciadores digitais entrevistados resgatam através das realizações, um sentido em continuar exercendo a carreira. É através dos prazeres vindo do trabalho que a profissão passa a ter um significado. Além disso, no momento que a vida pública começa a ser exposta, torna-se difícil não midiatizar também a vida privada. Ao expor seu cotidiano, o influenciador digital leva o seguidor para dentro da esfera pessoal, não delimitando mais fronteiras para esses dois espaços. Entretanto, é possível que o privado seja preservado até certo ponto, principalmente quando se refere às questões de sofrimento, que por muitas vezes não são exibidas nas redes.

\section{CONSIDERAÇÕES FINAIS}

Com o desenvolvimento do presente artigo foi possível compreender melhor sobre a recente profissão de influenciador digital, adentrando nesse universo. Foi realizada uma análise da trajetória acerca da profissão em questão, perpassando pela conceituação da profissão de influenciador digital, rotinas de trabalho, investimento e retorno financeiro, e desafios e realizações frente a carreira.

Foi constatado que é possível conceituar os influenciadores digitais como pessoas comuns, que através das redes sociais digitais influenciam pessoas em opiniões, estilo de vida e consumo. Eles alcançam um alto números de seguidores relatando e mostrando suas vidas e cotidianos, assim como fazendo propaganda para marcas e divulgando produtos. As empresas encontram nos influenciadores digitais um grande poder de venda, visto que os seguidores colocam nesses profissionais uma grande confiança, se identificando com tudo o que é mostrado. Através dos influenciadores digitais torna-se possível ligar a marca divulgada aos consumidores.

Em relação à rotina de trabalho, foi possível analisar que por se tratar de um trabalho majoritariamente realizado em casa, se faz necessário planejar com antecedência as publicações realizadas nas redes sociais, assim como a divulgação e propaganda das empresas. Além disso, por alguns influenciadores não terem essa profissão como exclusiva, torna-se ainda imprescindível adaptar horários e espaços para conciliar com os outros compromissos. 
Quanto aos custos de investimento para iniciar a carreira de influenciador digital, mostrou-se ser possível adentrar nessa profissão apenas com pequenos recursos tecnológicos, como um celular e câmera para fazer as gravações, além da internet para publicar nas redes sociais. Ademais, cursos de especialização e compra de roupas, promovendo a imagem passada nas redes, podem ser classificados também como uma opção de investimento.

No que se refere ao retorno financeiro, encontrou-se discordâncias sobre a profissão. Enquanto foi possível compreender que a carreira de influenciador digital pode trazer uma alta monetização e ser uma profissão rentável, também se percebe a existência de uma baixa remuneração para algumas pessoas, principalmente para quem está no início da carreira. Dessa forma, pode-se analisar que essa discrepância pode ser justificada por se tratar de uma profissão recente e ainda não ser encontrado um padrão de remuneração. Além disso, pode-se concluir que a principal fonte de renda dos influenciadores são as publicações em parceria com as marcas, assim como as divulgações dos produtos.

Visto que no trabalho é possível encontrar vivências de prazer e sofrimento, analisou-se ainda os principais desafios e realizações da carreira dos influenciadores digitais. Em relação aos desafios, foram pontuados alguns aspectos em comum, como as críticas recebidas e a necessidade de agradar a todo tempo, além da falta de compreensão das pessoas sobre a carreira. Como realizações, pode-se compreender que o contato com o público, a conexão de pessoas e o reconhecimento pelo trabalho trazem uma nova significação aos desafios, resgatando através dos prazeres o sentido de continuar a exercer a profissão.

Em relação ao reconhecimento da profissão, citado anteriormente, analisou-se que atualmente o público no geral já compreende mais o papel do influenciador digital, se comparado há alguns anos, onde era confundida apenas com lazer e se pensava que não existia esforço e dedicação na profissão. Entretanto, percebe-se que ainda é necessário continuar percorrendo o caminho da desmistificação e quebra do estereótipo, pois analisou-se também que por vezes a profissão ainda não é respeitada e valorizada. Conclui-se dessa forma que o reconhecimento do influenciador digital ainda passa por um processo de construção, tanto pelas marcas quanto pelo público.

Além disso, compreendeu-se que dentro da profissão de influenciador digital os segmentos da vida pública e privada se misturam. Quando o profissional expõe sua vida pública, fica difícil não levar para a mídia sua vida pessoal também, visto que parte das atividades da profissão se referem a mostrar sua rotina de vida e levar o seguidor para o cotidiano do influenciador. Desse modo, não existe mais barreiras entre vida pessoal e privada, porque é levado à público até mesmo as questões mais intimas do influenciador. Entretanto, encontrou-se ainda que por vezes a esfera pessoal pode ser preservada em momentos pontuais, como em relação aos momentos de tristeza e sofrimento, que em sua maioria, são evitados de ser expostos, sendo levado à público os momentos de alegria e empolgação.

Por fim, ressalta-se a relevância da temática como um todo, visto que compreender como a recente profissão de influenciador digital funciona, é também compreender as questões mais subjetivas da carreira, que perpassa as singularidades da profissão. Conclui-se que os objetivos da pesquisa 
foram alcançados, sendo possível a análise dos mais diversos aspectos citados referentes ao conceito e ao papel da profissão na vida do influenciador. Levando em conta a atualidade da temática, sugere-se ainda a ampliação de estudos e debates sobre a mesma, visto que a informação é uma maneira eficiente de trazer conhecimento e compreensão sobre a profissão de influenciador digital.

\section{REFERÊNCIAS}

BARDIN, L. Análise de conteúdo. São Paulo: Almedina Ed, 2011.

BENDASSOLLI, Pedro F.. Reconhecimento no trabalho: perspectivas e questões contemporâneas. Psicol. estud., Maringá , v. 17, n. 1, p. 37-46, Mar. 2012 . Available from: https://bit.ly/31IkZch. Access on: 02 Mar. 2020. http://dx.doi.org/10.1590/S1413-73722012000100005.

CINTRA, F. C. Marketing digital: a era da tecnologia on-line. Investigação, v. 10, n. 1, p. 6-12, 2010. COSTA, L. M., DIAS, M. M. da S., SANTOS, E. A., ISHII, A. K. S., SA, J. A. da S. A evolução do marketing digital: Uma estratégia de mercado. XXXV Encontro Nacional de Engenharia de Produção, Fortaleza, 2015.

DEJOURS, C. A Loucura do Trabalho: Estudo de Psicopatologia do Trabalho. São Paulo: Cortez, 1987.

DEJOURS, C. De la psychopathologie à la psychodynamique du travail. Posfácio à segunda edição de Traväil, usure mentale. Centurion, Paris, 1992.

DREYER, B. M. Relações públicas e influenciadores digitais: abordagens para a gestão do relacionamento na contemporaneidade. Faculdade Cásper Líbero, Brasil. Revista Communicare, 17(70), 2017.

EVANGELISTA, J. K. S., FERREIRA, J. R., COSTA, J. F., NASCIMENTO, B. R. Tensões entre o Público e o Privado a partir de um estudo de caso da Digital Influencer Nara Marques. In: XIX Congresso de Ciências da Comunicação na Região Nordeste. Fortaleza, CE. INTERCOM, 2017.

FERREIRA, A. B. H. Dicionário da língua portuguesa. 5. ed. Curitiba: Positivo, 2010.

FEREIRA, E. A., GRANGEIRO, R. R., PEREIRA, R. Influenciadores Digitais: Análise da profissão de uma nova categoria de trabalhadores. Revista Perspectivas Contemporâneas, 14(2), p. 04-23, 2019 
FILION, L. J. Empreendedorismo: empreendedores e proprietários-gerentes de pequenos negócios. Revista de Administração da USP, 34(2), p. 05-28, 1999.

GERNET, I., DEJOURS, . C. Avaliação do trabalho e reconhecimento. In: Clínicas do trabalho. P. F. Bendassolli \& L. A. Soboll (Orgs.), São Paulo: Atlas. 61-70, 2011.

GIL, A, C. Métodos e técnicas de pesquisa social. São Paulo: Atlas, 1999.

HISRICH, R. D., PETERS, M. P., SHEPHERD, D. A. Empreendedorismo. Tradução de Tereza Cristina Feliz de Sousa. 7. ed. Porto Alegre: Bookman, 2009.

HORNHARDT, N. A. Opinião e Esfera Públicas: Uma análise do poder da performance do influenciador digital. In: XLII Congresso Brasileiro de Ciências da Comunicação. Belém, PA. INTERCOM, 2019.

KARHAWI, I. Blogueiras de Moda no Brasil: a consolidação de uma profissão. In: Congresso de Iniciação Científica em Design e Moda, Anais, João Pessoa: UNIPÊ, p. 01-15, 2016.

KARHAWI, I. Influenciadores digitais: conceitos e práticas em discussão. Revista Communicare, São Paulo: Faculdade Clásper Líbero, 17, p. 46-61, 2017.

KUBO, S. H., GOUVÊA, M. A. Análise de fatores associados ao significado do trabalho. Revista de Administração. São Paulo, 47(4), p. 540-554, 2012.

LIMA, N. C. Influenciadores digitais e redes sociais: uma ponte formadora de opinião. Monografia (Especialização em Marketing Digital) - Instituto CEUB de Pesquisa e Desenvolvimento, Centro Universitário de Brasília, Brasília, 2016.

MENDES, A. M. Aspectos psicodinâmicos da relação homem-trabalho: as contribuições de C. Dejours. Psicol. cienc. prof., Brasília, 15(1-3), p. 34-38, 1995.

MENDES, A. M. Da psicodinâmica à psicopatologia do trabalho. In: Psicodinâmica do Trabalho: teoria, método e pesquisas. São Paulo: Casa do Psicólogo. p. 29-48, 2007.

MENDES, A. M., PAZ, V. C., BARROS, P. C . Estratégias de enfrentamento do sofrimento no trabalho bancário. Revista Estudos e Pesquisas em Psicologia, 3(1), p. 38-48, 2003. 
MOREIRA, T., RIOS, R. A Construção da Celebridade Midiática no Contexto dos Digital Infleuencers. In.: XXXIX Congresso Brasileiro de Ciências da Comunicação. São Paulo, SP. Anais. São Paulo: INTERCOM, 2016.

MOURÃO, Jr. C. A. Questões em bioestatística: o tamanho da amostra. Revista Interdisciplinar de Estudos Experimentais - Animais e Humanos, 1(1), p. 26-28, 2009.

NEVES, L. B. Influenciadores digitais como estratégia de marketing: quais são os efeitos no comportamento do consumidor? Trabalho de Conclusão de curso - Universidade Federal do Rio de Janeiro, Rio de Janeiro, 2019.

OLIVEIRA JUNIOR, F. E. As intenções empreendedoras na carreira de digital influencer. Administração, empreendedorismo e inovação 2 [recurso eletrônico] / Organizador Clayton Robson Moreira da Silva. Ponta Grossa (PR): Atena Editora, v. 2, p. 1-14, 2019.

QUIRINO, G., PINHEIRO, W. M. A Influência da Rede de Blogs no Consumo de Produtos e Marcas de Maquiagem. Revista Temática, 13(03), 2017.

RAFALSKI, J. C., ANDRADE, A. . Home-office: aspectos exploratórios do trabalho a partir de casa. Temas em Psicologia, 23(2), p. 431-441, 2015.

RIBEIRO, I, F. Análise do trabalho das influenciadoras digitais da região sul fluminense. Trabalho de Conclusão de Curso (Graduação em Psicologia) -Instituto de Ciências Humanas e Sociais, Universidade Federal Fluminense, 2018.

SHANE, S., LOCK, E. A., COLLINS, C. Entrepreneurial motivation. Human Resource, Management Review, 13(2), p. 257-279, 2003.

SILVA, C. R. M da., TESSAROLO, F. M. Influenciadores Digitais e as Redes Sociais Enquanto Plataformas de Mídia. In.: XXXIX Congresso Brasileiro de Ciências da Comunicação. São Paulo, SP. Anais... São Paulo: INTERCOM, 2016.

THOMPSON, J. B. A mídia e a modernidade: uma teoria social da mídia. Petrópolis: Vozes, 2013.

VILCHES, L. Tecnologia digital: perspectivas mundiais. Comunicação \& Educação, 26, p. 43-46, 2003. 